OPEN ACCESS

Edited by:

Chunyi Zhi,

City University of Hong Kong,

Hong Kong

Reviewed by:

Yang Huang,

Shenzhen University, China

Yagang Yao,

Nanjing University, China

*Correspondence:

Javad Forough

foroughi@uow.edu.au

Specialty section: This article was submitted to

Energy Materials,

a section of the journal

Frontiers in Materials

Received: 16 April 2019

Accepted: 29 May 2019

Published: 18 June 2019

Citation:

Lu Z, Raad R, Safaei F, Xi J, Liu Z and Foroughi J (2019) Carbon Nanotube

Based Fiber Supercapacitor as

Wearable Energy Storage.

Front. Mater. 6:138

doi: 10.3389/fmats.2019.00138

\section{Carbon Nanotube Based Fiber Supercapacitor as Wearable Energy Storage}

\author{
Zan $L u^{1}$, Raad Raad ${ }^{2}$, Farzad Safaei ${ }^{2}$, Jiangtao $X i^{2}$, Zhoufeng $L i u^{3}$ and Javad Foroughi ${ }^{2,4 *}$ \\ ${ }^{1}$ School of Fashion Engineering, Shanghai University of Engineering Science, Shanghai, China, ${ }^{2}$ Faculty of Engineering and \\ Information Sciences, School of Electrical, Computer and Telecommunications Engineering, University of Wollongong, \\ Wollongong, NSW, Australia, ${ }^{3}$ School of Textile Engineering, Zhongyuan University of Technology, Zhengzhou, China, \\ ${ }^{4}$ Intelligent Polymer Research Institute, Australian Institute for Innovative Materials, University of Wollongong, Wollongong, \\ NSW, Australia
}

Energy storage is a key requirement for the emerging wearable technologies. Recent progress in this direction includes the development of fiber based batteries and capacitors and even some examples of such fibers incorporated into prototype textiles. Herein we discuss the advantages of using the wet-spinning process to create nanostructured carbon based materials as wearable energy storage. The ability to control the physical, mechanical, electrical, and electrochemical properties of carbon nanotube based fibers holds great promise to develop smart polymeric structure as an energy storing materials including fibers and textiles. This is the first comprehensive review to discuss effect of nanostructured energy materials on the electrochemical properties of carbon nanotube based fibers which covers the various compositions, spinning and fabrication conditions on the performance of wearable energy storage.

Keywords: carbon nanotubes, energy storage, wearable technologies, supercapacitor, fiber spinning

\section{INTRODUCTION}

Today's "wearable technologies" mostly consist of electronic devices like wrist bands for fitness and health monitoring. However, it is predicted that in the coming years the fastest growing industry sector will be smart garments, where electronics are incorporated into the fabrics. Recently, leading fashion house Ralph Lauren released a health monitoring sports shirt that incorporates a fabric strain sensor. While functional, the shirt also required a separate and bulky Bluetooth communications module and battery pack for power. The growth projections for smart garments are based around seamless and invisible integration of the electronic functionality into the garments, without losing their aesthetic appeal and comfort (i.e., "fashion"). A particularly high priority is to develop wearable energy storage systems as these are the critical component of future wearable electronics. Consequently, the study of wearable energy storage devices has been under-taken by researchers around the world in recent decades in a quest to meet growing demands in the field of biomedical devices as well as communication and entertainment systems. To develop wearable energy storage, fiber-based or wire-shaped device can be easily integrated into stretchable yarns or fabrics to fulfill a more practical demand of wearable energy storage, conversation or transition in our daily life. Therefore, stretchable and bendable supercapacitors or batteries are two typical energy storage devices used in practical applications while composition and structure of materials used are critical in determining stretchability. 
Supercapacitor as one of the most promising energy storage technologies, with relatively high charge-discharge speed and power density has been widely researched. Fiberbased supercapacitors can seamlessly be incorporated in smart garments owing to the softness, knittability, or weavability of the fiber electrodes. The selection of materials is important to manufacture a fiber electrode, which can influence the electrochemical properties of the device (Dalton et al., 2003; Zhang et al., 2010). From one-dimensional fibers and yarns to two- or three-dimensional fabrics, numerous raw materials including natural and synthetic substances can be used as electrode materials for flexible supercapacitors in wearable devices. The development of electrode materials for fiberbased supercapacitors can reflect its practical application value in the following three aspects: (1) the diversity of fiber materials, which can be utilized to develop supercapacitors with different characteristics to compensate for the differences between materials; (2) The structural advantages of the fiber can realize the flexibility in three-dimensional direction to adapt to a variety of product designs, and can also be manufactured into fabrics with good wearability by traditional textile technology; (3) based on existing textile technologies, the mass production of fiber can primely promote the industrialization of flexible energy storage devices. Carbon nanotube fibers, acted as a conductor and substrate, have been demonstrated with supreme flexibility and stiffness as well as the easy post-treatment to combine with active materials comparing with the metal wires (Huang et al., 2015, 2016). Here, we will mainly discuss the processes and novel methods used to fabricate fibers composed of carbon nanotubes and the additional nanostructured energy materials for fabrication of the fiber-based supercapacitor.

\section{CARBON NANOTUBE FIBER-BASED SUPERCAPACITOR}

\section{Synthesis of Carbon Nanotube}

Carbon nanotubes (CNT) were discovered by Iijima in 1990s (Iijima, 1991), and have been utilized in a variety of applications such as actuators, artificial muscles, and lightweight electromagnetic shields (Foroughi et al., 2011, 2016; Haines et al., 2014; Sun et al., 2015). The preparation methods of carbon nanotubes basically use energy to decompose the carbon source into atomic or ionic forms, and then condense into a onedimensional structure of carbon. At present, three most popular fabrication methods have been utilized to obtain large-scale carbon nanotubes, which are, Arc Discharge method (Chhowalla and Unalan, 2011), Laser Ablation method (Danilov et al., 2014) and Chemical Vapor Deposition (CVD) method (Kumar and Ando, 2010). CNT prepared by different methods significantly vary with respect to their structure and properties. Generally, carbon nanotubes prepared by arc discharge method and laser ablation method have high crystallinity and straightness, but these methods suffer from low yield. CVD has achieved industrial production of carbon nanotubes. However, due to the low growth temperature, the prepared carbon nanotubes have a poor degree of graphitization with many defects on ends and surfaces. In

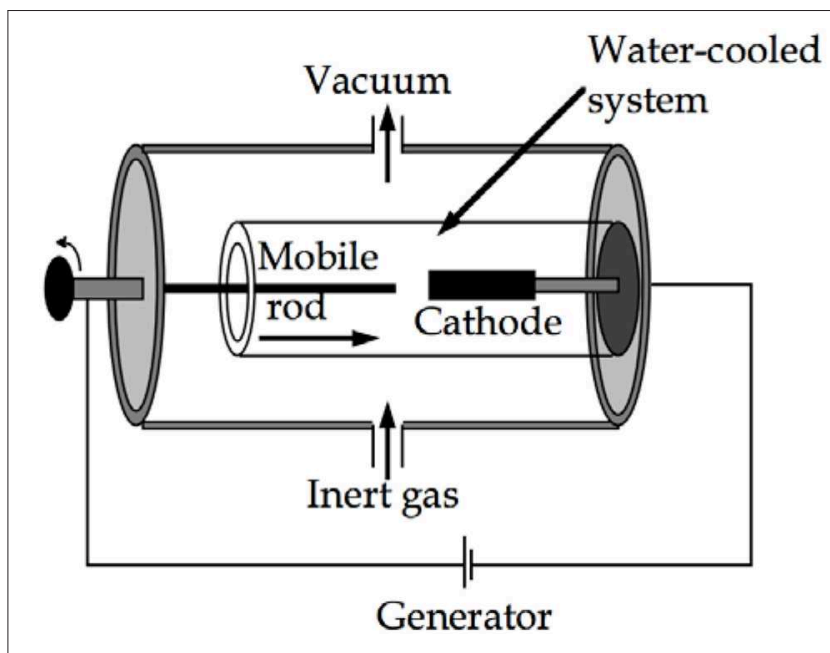

FIGURE 1 | Schematic progress of CNT formation by arc-discharge method (Journet and Bernier, 1998).

the preparation process, catalyst particles are often introduced, which are difficult to be removed and affect the properties and further applications of carbon nanotubes.

\section{Arc Discharge Method}

In arc discharge method, a vacuum reaction chamber is filled with an inert gas or hydrogen, two graphite rods act as a cathode and an anode, respectively, and a DC voltage is applied to the graphite electrode resulting in a strong electric arc (as shown in Figure 1). During the arc discharge, the graphite rod of the anode is continuously evaporated at high temperature generated by the arc, and the product containing carbon nanotubes is subsequently deposited on the cathode. Generally, the purity and yield of multi-walled carbon nanotubes (MWNTs) are susceptible to the inside pressure of the reaction vessel (Ebbesen and Ajayan, 1992). Shimotani et al. (2001) found that the yield of MWNTs increased with the increasing gas pressure in the reaction vessel ranged from 150 to 400 Torr for all organic gases. In addition to DC arc discharge, pulsed arcs can also be utilized to prepare MWNTs in the atmosphere (Parkansky et al., 2004). Moreover, some reports shown that high-purity MWNTs can be prepared on a large scale in liquid gases such as liquid nitrogen (Jung et al., 2003).

The preparation of SWNTs by arc discharge method usually requires a transition metal catalyst, and the anode generally is made of a composite material, such as graphite composited with a commercial metal like $\mathrm{Ni}, \mathrm{Fe}, \mathrm{Co}, \mathrm{Ag}, \mathrm{Pt}$, or a composite of two metals, such as $\mathrm{Co}-\mathrm{Ni}$, Fe-Ni, Fe-No, Co-Cu, Ni-Cu, etc. (Ando et al., 2004). In order to ensure the high efficiency of production, it is necessary to guarantee a stable current density and anode consumption rate during the reaction process so that a constant spacing between the electrodes should be maintained. Although the production of carbon nanotubes by arc discharge method has gradually become more and more mature by adjusting the preparation conditions in terms of catalyst, electrode size, electrodes spacing, and types of raw materials, 


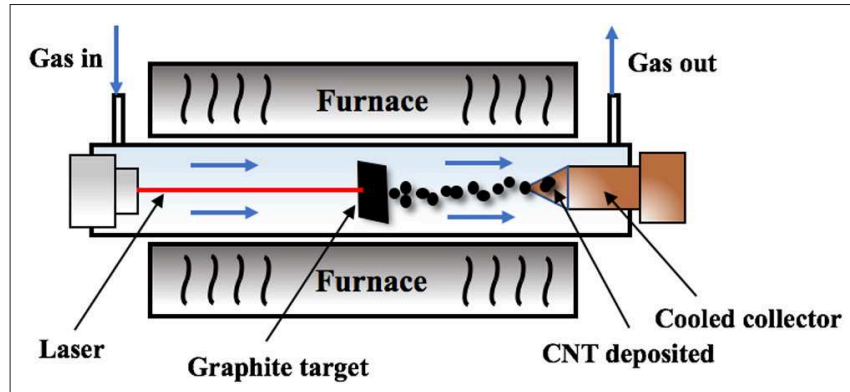

FIGURE 2 | Schematic diagram of CNT formation progress by laser ablation method.

the yield of carbon nanotubes produced by such method is relatively low due to the difficulties in arc control and high cost of fabrication (Pillai et al., 2008).

\section{Laser Ablation Method}

High-quality and high-purity SWNTs can be prepared using laser ablation, which was first proposed by Smalley's team in 1995 (Guo et al., 1995; schematically shown in Figure 2). With the similar principle and mechanism of arc discharge method, carbon nanotubes produced by laser ablation method exhibit a relatively high crystallinity and straightness. In this method the energy is generated by hitting a graphite target containing catalytic materials (such as nickel and cobalt) with a specific wavelength of laser (Guo et al., 1992). Transition metals such as Fe, Co, and $\mathrm{Ni}$ are firstly doped as a catalyst into the graphite target and placed in the reactor. The surface of the target is bombarded with a laser when the reaction temperature reaches $2,000^{\circ} \mathrm{C}$ under the protection of an inert gas (such as He; Thess et al., 1996). The formed gaseous carbon and catalyst particles are then brought from the high temperature zone to the low temperature zone by the gas flow, at which time the gaseous carbons are collided with each other to form carbon nanotubes in the carrier gas under the action of the catalyst.

The performance of CNTs prepared by laser ablation is mainly affected by the following parameters: laser parameters (energy fluence, peak power, continuous wave and pulse wave, repetition rate, oscillation wavelength), pressure and material composition of the combustion chamber, structure and chemical composition of the target material, flow and pressure of the buffer gas, spacing between target material and matrix, and the temperature of matrix and ambient (Ikegami et al., 2004).

\section{Chemical Vapor Deposition Method}

The CVD method has attracted significant interest by researchers. This method mainly uses a hydrocarbon substance as a carbon source to be cleaved into carbon clusters on the surface of the catalyst particles and then regrouped when the carbon source gas is in contact with the catalyst in the quartz tube at a suitable temperature (shown in Figure 3; Ando et al., 2004). A transition metal such as iron, cobalt, nickel, molybdenum, niobium, and tantalum is generally used as a catalyst. The experimental results show that the size of the metal catalyst particles predominantly determines the inner and outer diameter of the carbon nanotubes. Therefore, carbon nanotubes with higher purity and uniform size distribution can be grown by selectively controlling the type and particle size of the catalyst (Steiner et al., 2009).

Compared with other methods, CVD method has the advantages of easy-control of reaction process, simple and convenient preparation apparatus, relatively low growth temperature and high purity, low cost, strong adaptability, and large-scale production. The method also has the ability to align carbon nanotubes arrays by controlling the application of catalysts and increase the density of the array by liquid-induced process (Yao et al., 2007; Zhang K. et al., 2017), which has been widely used in the preparation of carbon nanotubes (Prasek et al., 2011; Das et al., 2016).

\section{Carbon Nanotube Based Fibers}

Carbon nanotubes have been widely utilized as electrode materials owing to their extraordinary physical and chemical properties, and assemblies of CNTs in fiber format have been shown to be a viable platform to take these properties from the nanoworld to macroscopic scale (Jarosz et al., 2011, 2012; Lu et al., 2017). As the electrode materials, the conductivity and strength of CNT fibers should be satisfied with the requirement of supercapacitor. The formation of carbon nanotube based fiber can be divided into wet-spun method and solid-state spun method.

\section{Wet-Spun CNT Fibers}

Wet-spinning as one of the conventional fiber fabricating methods, and can enlarge the yield of fibers. A $60 \mathrm{wt} \%$ carbon nanotube (prepared by arc discharged method) contained fiber was firstly developed by Vigolo and co-workers, in which the fiber were prepared by extruding the surfactant-stabilized singlewalled carbon nanotube (SWNT) solution into a PolyVinyl Alcohol (PVA) coagulation bath (Vigolo et al., 2000). In previous researches, dispersing CNTs with polymers or surfactant could form a stable spinning solution, the composite fibers were prepared by following extrusion into coagulation bath and extension (Vigolo et al., 2002; Dalton et al., 2003; Miaudet et al., 2005). With the existence of polymers, large-molecule surfactant, the electrical, and thermal conductivity of the fiber was extremely poor although the mechanical properties were reasonable owing to the enhancement of CNTs. Using this technology, the existing polymer can only be completely removed by thermal annealing that causes pyrolysis of the polymer, which will degrade the mechanical properties of the fibers by decreasing strength and modulus and making them rather brittle (Badaire et al., 2004; Munoz et al., 2004; Miaudet et al., 2005). Polymer-free carbon nanotube fibers can alternatively be achieved by utilizing a small molecule coagulation bath system (Steinmetz et al., 2005), $\mathrm{pH}$ adjusting flocculation-based process (Kozlov et al., 2005), super acid based wet-spun fabrication (Ericson et al., 2004; Ramesh et al., 2004; Davis et al., 2009; Parra-Vasquez et al., 2010; Behabtu et al., 2013; Ma et al., 2013; Bucossi et al., 2015). The spinning parameters can also draw an important role in the preparation, including the diameter and shape of needle or 


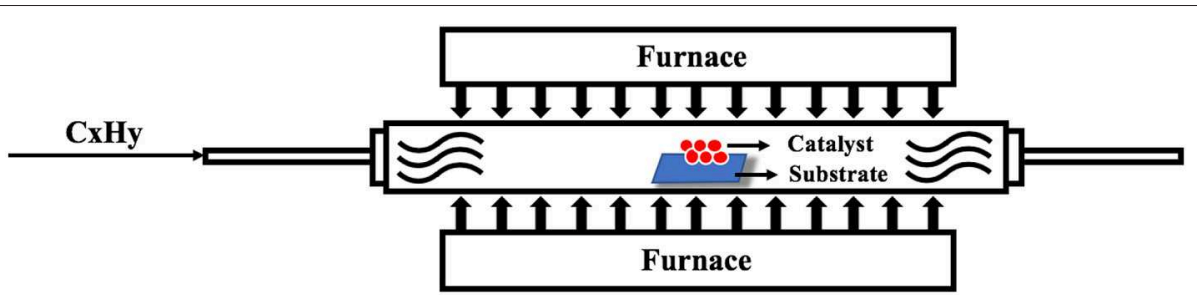

FIGURE 3 | Schematic diagram of CNT preparation of CVD method.

spinneret, extruding speed and rotating speed in rotate spinning method, which will affect the morphologies and performances of the obtained fibers (Kozlov et al., 2005).

\section{Solid-State Spun CNT Fibers}

CNT fibers prepared by solid-state spinning can be expanded with following methods: directly spinning from a CVD grown CNT aerogel; spinning from a vertical grown CNT arrays; twisting/rolling from "cotton" like CNT bundles or a CNT film. The carbon nanotubes can be self-assembled into fiber due to the van der Waals interactions, by which CNTs hold together to form aligned bundles.

Floating CVD was initially utilized to grow CNTs, Li et al. (2004) then developed a method to draw a fiber from the CNT aerogel formed in a vertical furnace with a purity of 85-95 wt\% of MWNTs inside, as well as a good electrical conductivity of $8.3 \times 10^{5} \mathrm{~S} / \mathrm{m}$. This direct spinning method can be used to obtain a variety of products including nanotube fibers, ribbons, and coatings. On this basis, Li and co-workers (Jang et al., 2009) improved the process and successfully achieved a few kilometers of CNT fiber, meanwhile the strength reached more than $1 \mathrm{GPa}$.

The key to directly spinning from carbon nanotube arrays is to prepare arrays that are uniform and enough material for continuous spinning (Zhang et al., 2004). Jiang et al. (2002) firstly drew a ultra-long CNT fiber from a spinnable CNT arrays with extraordinary electrical property. Twisted CNT sheets have been proved to enhance the strength of fibers, the height of the grown CNT arrays can also influence the mechanical performance of the fiber (Zhang et al., 2006; Ci et al., 2007). It is mainly due to the defects, which are the density of the end points on the grown ultra-long carbon nanotubes, are relatively low, so that the contact area of the adjacent carbon nanotubes is large to prevent the slipping of the bundles. Zhang et al. (2007) reported a strong, stiff, and lightweight CNT fiber, which was spun from a ultra-high $(1 \mathrm{~mm})$ individual CNTs forest. In addition, the density, diameter, number of walls, and the content of amorphous carbon of the carbon nanotubes in the array will affect the forming process of fibers and ultimately determine the properties of the CNT fibers (Zhang et al., 2008).

By using the ancient spinning approach, a CNT "cotton" was twisted into a fiber, regarding as the CNT assembles were readily transferred to fiber format (Zheng et al., 2007). The film-like CNTs similarly can be rolled or twisted into a fiber, which has been demonstrated by Ma et al. (2009). As followed by Feng et al. (2010), they developed another method by rolling a synthesized double-layered carbon nanotube (DWNT) film into a fiber, which had a superior electrical conductivity of $8.0 \times 10^{4} \mathrm{~S} / \mathrm{m}$.

Generally, the length, diameter, defects, and post-treatment of the prepared carbon nanotubes predominately affect the dispersion of CNT in aqueous or super-acid system to form continuous and uniform CNT fibers in the followed procedure. Besides, the strength, stiffness, and flexibility of the formed CNT fibers also determined by these characteristics of the prepared CNTs by utilizing the wet spinning method. Due to the specific fabrication approach of solid-spun CNT fibers, carbon nanotubes that are grown by CVD have been demonstrated as the major method to obtain the desired fibers. The fibers fabricated by wet spinning technology exhibit a higher electrical conductivity and lower mechanical properties compared to those of solid-state spun fiber, which can be illustrated in Table $\mathbf{1}$.

\section{Nanostructured Energy Materials in Fibers}

Although the stability and high power density of double-layered capacitance materials like carbon nanotube are demonstrated and well-known, the limitation of the energy density has been drew a wide attention to improve. Combing high electrochemical capacitance materials, such as graphene, active carbon (Ma et al., 2016), metal oxide, transition sulfide (Sun et al., 2014a, 2015), and conducting polymer, with prepared carbon nanotube based fibers can extremely enhance the specific capacitance of original fibers and maintain the cyclical properties meanwhile (Wang et al., 2013; Yao et al., 2015). In this part, we will mainly discuss the nanostructured energy materials used in fiber-based supercapacitor from the perspective of compositing approaches. We have summarized the different methods used for fiber electrode fabrication in Table 2 for easy comparison.

\section{Co-spinning}

With the features of self-stacking and self-assembling during the spinning process of carbon nanotube based fibers, which has been demonstrated to affect the electron exchange between ions and materials in the electrolyte, nanostructured energy materials can simultaneously incorporate with these carbonaceous materials by bonding or simply sticking. It is found that combining carbon nanotubes with two-dimensional sheet-like materials can prevent effective surface area reduction and capacitance loss caused by stacking of materials (Yu and Dai, 2009; Jha et al., 2012).

Peng and co-workers prepared a CNT/Graphene hybrid fiber by dip-coating the GO dispersions on the as-grown MWNT arrays and then spun to be a fiber by the approach as described 
TABLE 1 | Properties of carbon nanotubes in fiber formation for wearable applications.

\begin{tabular}{|c|c|c|c|c|c|}
\hline $\begin{array}{l}\text { CNT fabrication } \\
\text { method }\end{array}$ & $\begin{array}{l}\text { Fiber fabrication } \\
\text { method }\end{array}$ & $\begin{array}{l}\text { Tensile } \\
\text { strength (GPa) }\end{array}$ & $\begin{array}{l}\text { Young's } \\
\text { modulus (GPa) }\end{array}$ & $\begin{array}{l}\text { Electrical } \\
\text { conductivity }\end{array}$ & References \\
\hline CVD & Wet-spun & 1.8 & 80 & - & Dalton et al., 2003 \\
\hline Arc discharge & Wet-spun & 0.225 & 23 & $450 \mathrm{~S} / \mathrm{cm}$ & Lu et al., 2017 \\
\hline Arc discharge & Wet-spun & $0.14-0.16$ & $9-15$ & - & Vigolo et al., 2000 \\
\hline Arc discharge & Wet-spun & 0.23 & 40 & - & Vigolo et al., 2002 \\
\hline CVD & Wet-spun & $\begin{array}{l}1.8 \text { (SWNT), } \\
1.4 \text { (MWNT) }\end{array}$ & $\begin{array}{l}45 \text { (SWNT), } \\
35 \text { (MWNT) }\end{array}$ & - & Miaudet et al., 2005 \\
\hline CVD & Wet-spun & 0.026 & - & - & Munoz et al., 2004 \\
\hline Arc discharge & Wet-spun & Brittle & Brittle & $150 \mathrm{~m} \Omega \cdot \mathrm{cm}$ & Steinmetz et al., 2005 \\
\hline CVD & Wet-spun & 0.77 & 8.9 & $140 \mathrm{~S} / \mathrm{m}$ & Kozlov et al., 2005 \\
\hline CVD & Wet-spun & $0.116 \pm 0.01$ & $120 \pm 10$ & - & Ericson et al., 2004 \\
\hline CVD & Wet-spun & $1.0 \pm 0.2$ & $120 \pm 50$ & $2.9 \pm 0.3 \mathrm{MS} / \mathrm{m}$ & Behabtu et al., 2013 \\
\hline CVD & Wet-spun & $0.21-0.25$ & - & 4.1-5.0 MS/m & Bucossi et al., 2015 \\
\hline CVD & Solid-state & 0.1 & 1.0 & $0.83 \mathrm{MS} / \mathrm{m}$ & Li et al., 2004 \\
\hline CVD & Solid-state & $\begin{array}{l}0.15-0.3 \text { single } \\
0.25-0.46 \text { two-ply }\end{array}$ & - & $0.3 \mathrm{MS} / \mathrm{m}$ & Zhang et al., 2004 \\
\hline CVD & Solid-state & 0.6 & 74 & - & Jiang et al., 2002 \\
\hline CVD & Solid-state & 0.3 & 8.3 & - & Zhang et al., 2006 \\
\hline CVD & Solid-state & $\begin{array}{l}0.85 \text { untwisted, } \\
1.91 \text { twisted }\end{array}$ & $\begin{array}{l}275 \text { untwisted, } \\
330 \text { twisted }\end{array}$ & $\begin{array}{l}170 \text { S/cm untwisted, } \\
410 \text { S/cm twisted }\end{array}$ & Zhang et al., 2007 \\
\hline CVD & Solid-state & $0.5 \pm 0.1$ & $8.0 \pm 1.0$ & $500 \mathrm{~S} / \mathrm{cm}$ & Zhang et al., 2008 \\
\hline CVD & Solid-state & $\sim 0.19$ & - & - & Zheng et al., 2007 \\
\hline CVD & Solid-state & $0.55-0.8$ & $9-15$ & - & Ma et al., 2009 \\
\hline CVD & Solid-state & 0.112 & - & $800 \mathrm{~S} / \mathrm{cm}$ & Feng et al., 2010 \\
\hline
\end{tabular}

above (Sun et al., 2014b; shown in Figure 4A). Due to the strong interaction of the $\pi-\pi$ bond between the graphene oxide sheet and the carbon nanotube, the transfer efficiency of electrons in the composite fiber is greatly improved, and the graphene oxide sheet can reduce the stacking of the carbon nanotubes and increase the paths of ions. The tensile strength of the chemical-reduced hybrid fiber reached at $\sim 500 \mathrm{MPa}$ compared to that of bare CNT fiber $(\sim 630 \mathrm{MPa})$, meanwhile the electrical conductivity of the hybrid fiber can be achieved as high as $450 \pm 20 \mathrm{~S} / \mathrm{cm}$. The calculated specific capacitance of the hybrid fiber could be reached at $\sim 31.5 \mathrm{~F} / \mathrm{g}$ compared with $\sim 5.83 \mathrm{~F} / \mathrm{g}$ of the bare CNT fiber. Depending on the similar principle, Foroughi et al. (2014) explored a novel type of conductive carbon nanotube-graphene composite fiber by the electro-spinning of a chemical-reduced graphene within and cover the surface of MWNT fiber during the drawing procedure (Figure 4B). The electrical conductivity of prepared hybrid fiber could be reached at $900 \pm 50 \mathrm{~S} / \mathrm{cm}$, while the tensile strength, modulus and elongation at break of the fiber were about $140 \mathrm{MPa}, 2.58 \mathrm{GPa}$, and 6\%, respectively. The specific capacitance was dramatically improved to $111 \mathrm{~F} / \mathrm{g}$ at a scan rate of $2 \mathrm{mV} / \mathrm{s}$.

A wet-spinning process was proposed by $\mathrm{Ma}$ and co-workers to fabricate a CNT-rGO fiber (Ma et al., 2015). The pure fewwalled carbon nanotubes (FWNTs) with 3-5 walls were first dispersed in water with the assistance of ultrasonication, and then mixed with a GO solution that was synthesized from expanded graphite. The mixture was extruded into a chitosan/acetic acid coagulation bath to form a fiber with followed washing and drying. The interaction of FWNT and rGO sheets can dramatically increase the stress strength from 193.3 to $385.7 \mathrm{MPa}$ and electrical conductivity from 53.3 to $210.7 \mathrm{~S} / \mathrm{cm}$ compared to pristine rGO fiber by using the similar method, while the fiber based supercapacitor illustrated a specific capacitance of $38.8 \mathrm{~F} / \mathrm{cm}^{3}$.

As a good surfactant to disperse nitric-acid-treated SWNTs, GO dispersion, can homogenously be mixed with SWNTs as a aqueous suspension for composite fiber spinning. Yu et al. (2014a) proposed such suspension to be fed into homemade silica column and heated in an oven with optimal parameters (Figure 4C). The composite SWNT/rGO fiber was self-assembled by hydrothermal method and successively pushed into water by gas flow and further dried in air. The fiber enjoyed a tensile strength of $88 \mathrm{MPa}$, and the electrical conductivity was $\sim 100 \mathrm{~S} / \mathrm{cm}$ compared to that of SWNT fiber and rGO fiber, which are $50-150 \mathrm{MPa}$ and $\sim 12.5 \mathrm{~S} / \mathrm{cm}$, respectively. The assembled hybrid fiber supercapacitor expressed a ultra-high volumetric specific capacitance of $\sim 45.0 \mathrm{~F} / \mathrm{cm}^{3}$.

Recently, we used the violent exothermic reaction of chlorosulfonic acid and hydrogen peroxide to exfoliate the graphite powder to form graphene with a small number of layers, and mixed the prepared graphene and carbon nanotubes with the chlorosulfonic acid as a spinning solution. The graphene/carbon nanotube composite fiber was prepared by wet-spun technology with a three-dimensional structure, as shown in Figure 4D. It can be shown that electron channels were formed when 
TABLE 2 | Electrochemical performances of CNT fiber-based electrodes and supercapacitors in different fabrication and deposition methods.

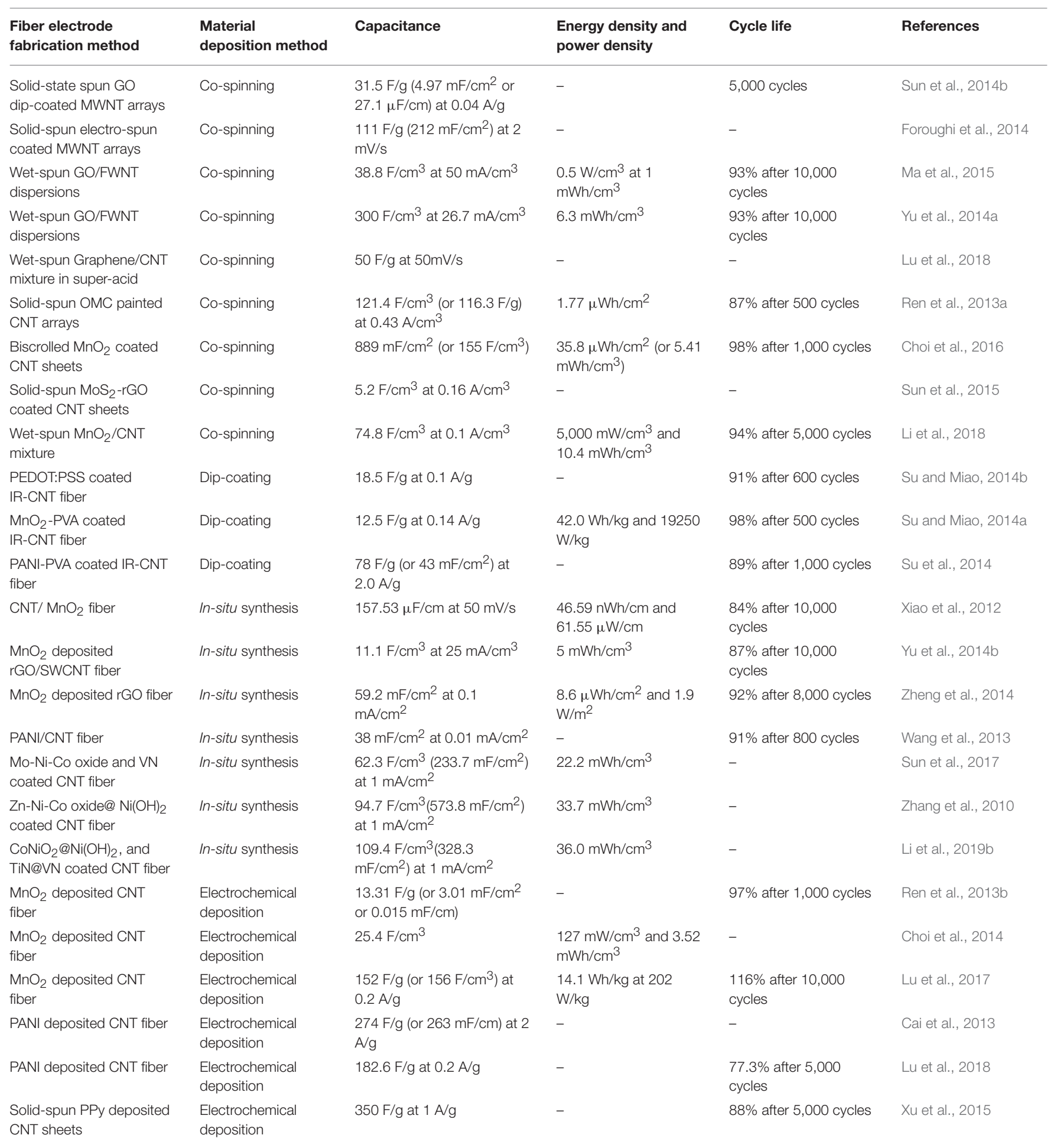

the two-dimensional graphene sheets stacked and upheld by the carbon nanotube bundles, leading to a good electrical and ionic conductivity. The specific surface area of the fiber cross section was greatly increased, and the specific capacitance of the composite fiber was thus increased by about $38 \%$ compared with the carbon nanotube fibers prepared by us previously (Lu et al., 2018).

With the assistance of nanoparticles or nanosheets, the co-spun CNT based fiber can also increase the integral electrochemical performances compared with the bare CNT 
A

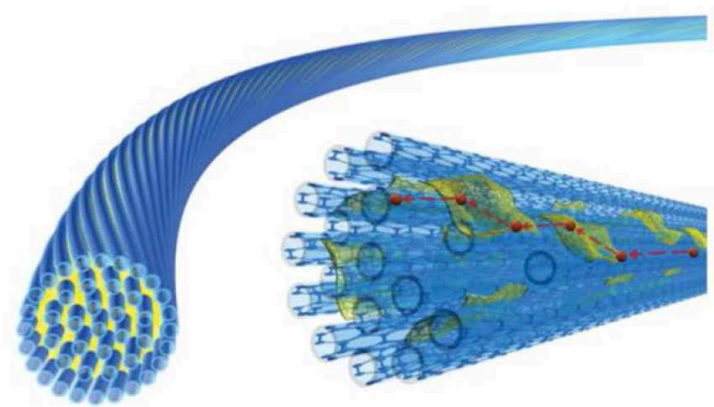

C

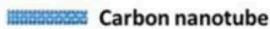

Graphene

- Charge

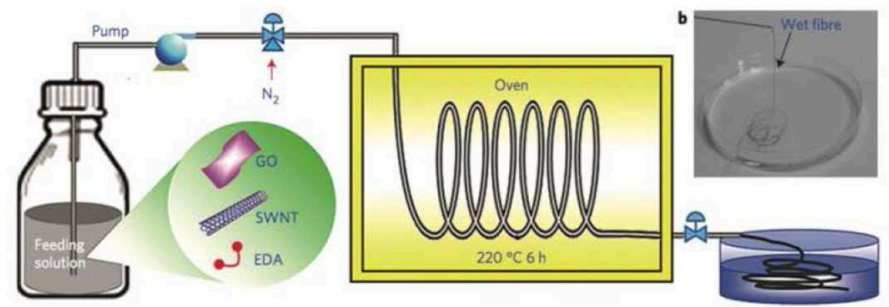

B

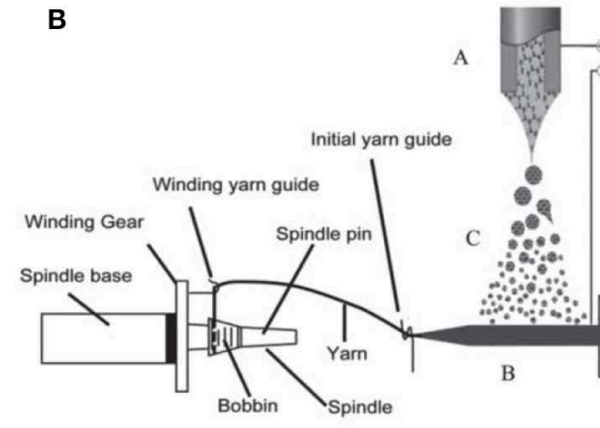

D

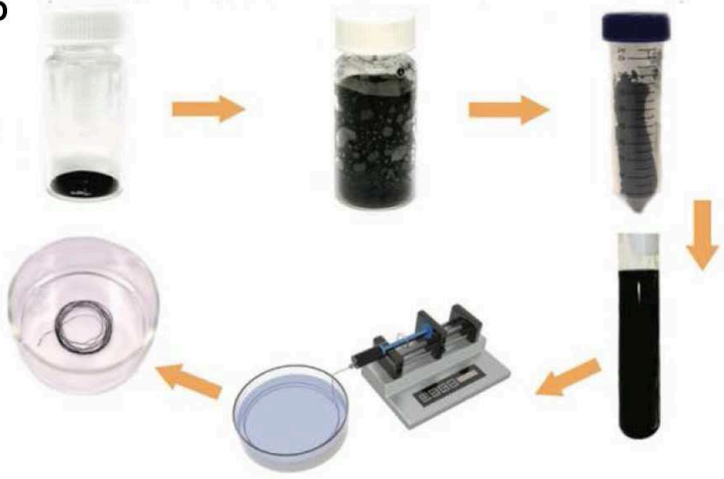

FIGURE 4 | Schematic illustration of (A) solid-spun carbon nanotube fiber with internal graphene sheets (Sun et al., 2014b). (B) Co-spinning of CNT/graphene hybrid fiber with solid-spun and electrospinning methods (Foroughi et al., 2014). (C) Hydrothermal procedures of rGO/SWNT composite fiber (Yu et al., 2014a). (D) Super-acid exfoliated graphene sheets co-spun with carbon nanotubes (Lu et al., 2018).

fiber. Ren et al. (2013a) creatively painted a suspension of ordered microporous carbon (OMG) on 10 layers of aligned CNT sheets that drawn from a spinnable CNT array and rolled the combined sheets into a hybrid fiber as one electrode. The electrochemical performances of the OMC/CNT hybrid fiber were investigated in a three-electrode system, which indicated a rectangular shaped $\mathrm{CV}$ curve even at a scan rate of $200 \mathrm{mV} / \mathrm{s}$. The prepared negative electrode enjoyed a specific volumetric capacitance up to 121.4 $\mathrm{F} / \mathrm{cm}^{3}$ (or $116.3 \mathrm{~F} / \mathrm{g}$ ) at $0.43 \mathrm{~A} / \mathrm{cm}^{3}$, which was controlled by the content of OMC particles in the hybrid fiber ( $~ 76 \mathrm{wt} \%)$.

Choi and co-workers also developed a novel method that biscrolled CNT sheets with drop casting of $\mathrm{MnO}_{2}$ dispersion into a fiber (shown in Figure 5; Choi et al., 2016). The strategy of biscrolling can dramatically expand the loading mass of active nanoparticles as high as $99 \mathrm{wt} \%$ without any influences on the mechanical properties of fiber. The biscrolled $\mathrm{MnO}_{2} / \mathrm{CNT}$ fiber was able to achieve a areal specific capacitance of $889 \mathrm{mF} / \mathrm{cm}^{2}$ (or $155 \mathrm{~F} / \mathrm{cm}^{3}$ ) and possessed an energy density of $35.8 \mu \mathrm{Wh} / \mathrm{cm}^{2}$ (or $5.41 \mathrm{mWh} / \mathrm{cm}^{3}$ ).

Sun et al. (2015) pre-coated the $\mathrm{MoS}_{2}$ nanosheets, which are dispersed in DMF, on the carbon nanotubes arrays during the spinning process. The prepared composite fibers had significantly improved the volumetric specific capacitance. $\mathrm{Li}$ et al. also illustrated a cathode active material $\left(\mathrm{V}_{2} \mathrm{O}_{5}\right)$ enhanced CNT fiber by wet-spinning method, which shown a maximum energy density of $1.95 \mathrm{mWh} / \mathrm{cm}^{3}$ at a power density of $7.5 \mathrm{mWR} / \mathrm{cm}^{3}$, although the PVA based coagulation bath relatively influenced the conductivity of the fiber ( $\mathrm{Li}$ et al., 2017). Recently, Chen's Group prepared a $\mathrm{MnO}_{2} / \mathrm{CNT}$ fiber by mixing the nanosheet structured $\mathrm{MnO}_{2}$ with SWNT dispersion to form a spinning solution for wet spinning. The fabricated fibers had a content of active substance with more than 75\% (Li et al., 2018).

The co-spinning method can be appropriate for solidstate spinning and wet spinning of CNT fibers by mixing or casting active materials dispersed solution with intrinsic spinnable suspension or arrays. CNT fibers have the feasibility to be incorporated with the nanostructured materials during the wet spinning, hydrothermal reactions (with graphene) and assembling process. Consequently, such approach can be considered to apply a various of functional materials into the CNT based fibers (Figures 5d,e).

\section{Dip-Coating}

As we known, the obtained CNT based fibers have a potential to embrace with the nanostructured energy materials. Dipcoating, as one of the most utilized methods to compose different substances, has been frequently reported and relatively effective than co-spinning (Peng et al., 2009; Guo et al., 2012; Li et al., 2012). PEDOT, as a conducting polymer with good film forming properties, high concentration in aqueous solution, accompanied with high stability and conductivity, has attracted a lot of interests 

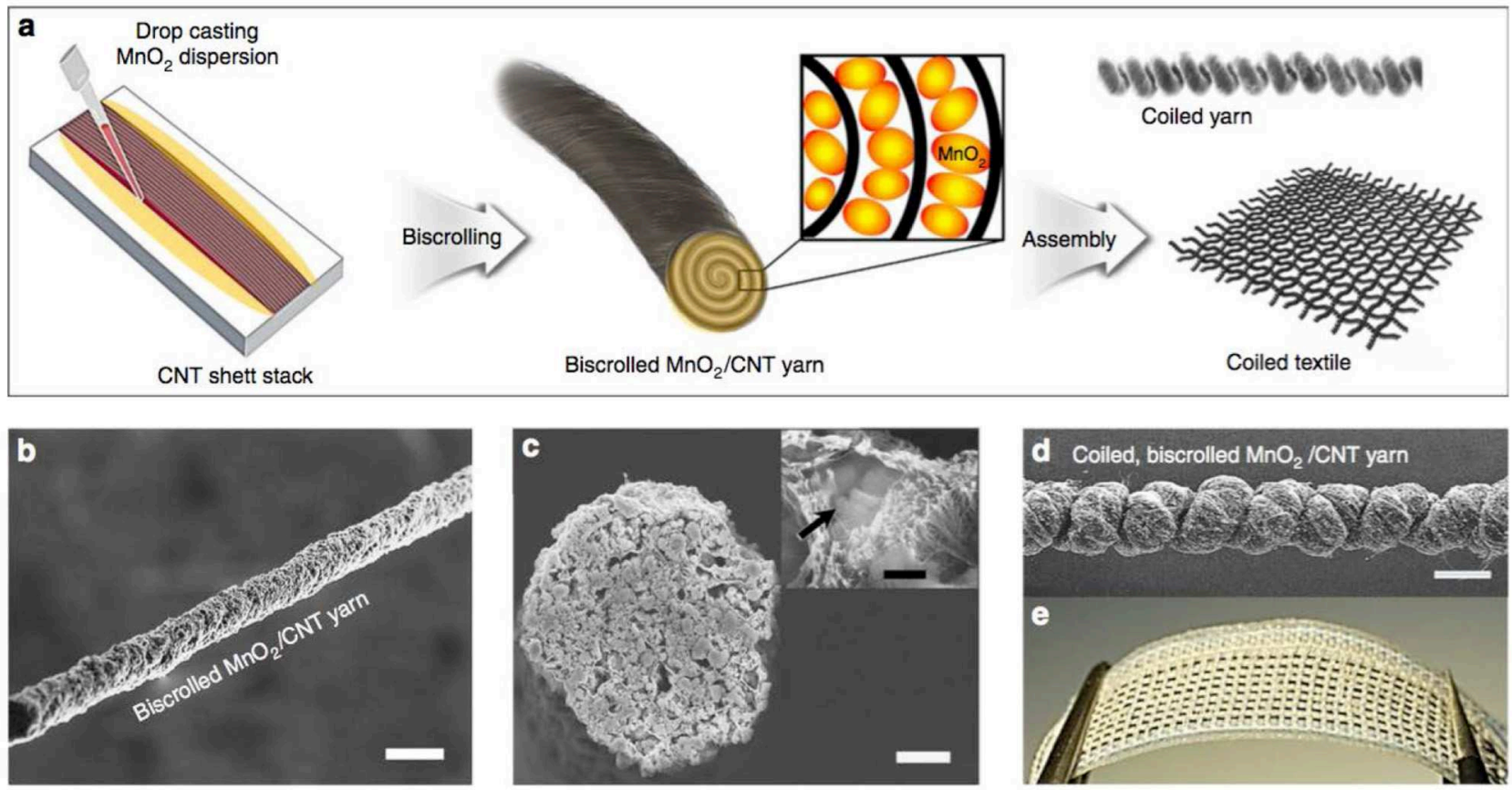

FIGURE 5 | Schematic showing the (a) preparation and structure of biscrolled CNT/MnO 2 hybrid fiber, SEM morphologies of (b,c) as-spun biscrolled hybrid fiber and (d,e) two-ply coiled yarn integrated in a fabric (Choi et al., 2016).

A

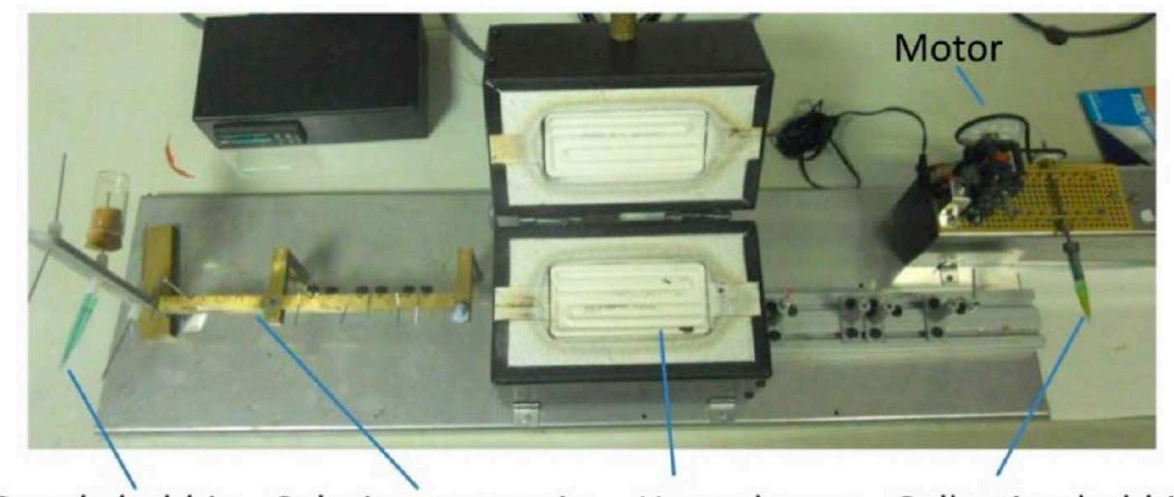

Supply bobbin Solution reservoir Heated oven Collection bobbin

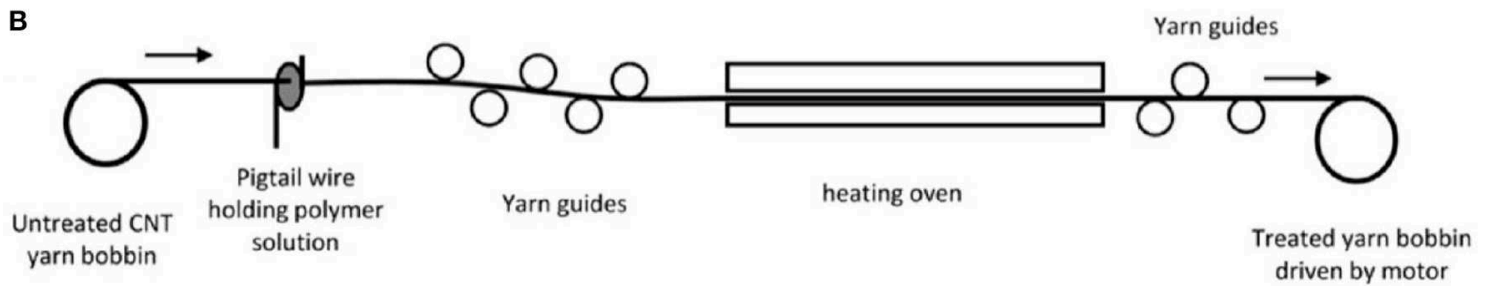

FIGURE 6 | (A) Photograph and (B) schematic diagram of the continuous dip-coating process apparatus for hybrid fiber fabrication (Su et al., 2014).

recently. The salt doped PEDOT has been proved to be directly spun into a conductive fiber and well film-forming (Jalili et al., 2011, 2012, 2013). Su and Miao (2014b) used the commercial PSS doped PEDOT solution as a doping medium, in which $\mathrm{SO}_{3} \mathrm{H}$ groups improved the electroactivity of principal conducting polymer in a neutral electrolyte due to the "doping effect" of PSS, and a gamma-irradiated CNT fiber as a current collector to produce a fiber-based supercapacitor (demonstrated in Figure 6). 
The easy preparation of fiber electrode could be scaled up and the existing of PEDOT and CNT illustrated a rectangular-shape of $\mathrm{CV}$ curves as well as remarkable fast charge-discharge properties during electrochemical measurement. The gravimetric specific capacitance of the supercapacitor achieved at $18.5 \mathrm{~F} / \mathrm{g}$, which was almost twice compared to that of bare irradiated CNT fiber supercapacitor $(9.2 \mathrm{~F} / \mathrm{g})$.

To enhance the adhesion of the applied electrochemical active materials on the fibers, polymer-assisted dispersions are good medium to be further utilized for dipping and coating. Meanwhile, the format of asymmetric fiber supercapacitor can extend the operating potential window and result in much higher energy and power densities of the whole device. Su and Miao (2014a) dispersed a mass of $\mathrm{MnO}_{2}$ nanoparticles in PVA solution by vigorous stirring to form a uniform $\mathrm{MnO}_{2}$-PVA paste. The asspun CNT fibers were then dip-coated with the prepared paste by a self-designed set-up, and the obtained $\mathrm{CNT} / \mathrm{MnO}_{2} / \mathrm{PVA}$ fiber electrode was twisted with a bare CNT fiber by overall casting of a gel electrolyte to form an asymmetric supercapacitor. This type of supercapacitor expressed a wide operating potential window of $2.0 \mathrm{~V}$ and the highest energy and power densities reached 42.0 $\mathrm{Wh} / \mathrm{kg}$ and 19,250 W/kg, respectively. With the similar method, they synthesized PANI nanowire solution beforehand the fiber spinning, the obtained irradiated CNT fiber was orderly covered with PANI-PVA and PVA gel electrolyte. The composited fiber revealed a gram specific capacitance of $78 \mathrm{~F} / \mathrm{g}$ ( or $43 \mathrm{mF} / \mathrm{cm}^{2}$ ), which was almost twice comparing to that of a bare CNT/PANI fiber based supercapacitor (Su et al., 2014).

The dip-coating method can not only fill the interspaces in carbon nanotube based fibers, but also enhance the mechanical properties of the original fibers by specifically selecting filmforming solutions. Many active materials are insoluble or reactive in aqueous dispersions by using co-spinning; dip-coating can alternatively be chosen to incorporate such materials with suitable solvent.

\section{In-situ Compositing}

In-situ composition is derived from the concepts of in-situ crystallization and in-situ polymerization. The second phase in the material of the composite is formed during the formation of the material or synthesized on a substrate. The in-situ formation may be a phase of metal (Randeniya et al., 2010; Xu et al., 2011; Zhang et al., 2012, 2014; Chen et al., 2013), ceramic or polymer (Cai et al., 2013), which may be presented in the matrix in the form of microstructures such as particles, whiskers, crystal plates or microfibers. For fiber based electrodes, in-situ synthesis and electrochemical deposition have been generally utilized for enhancing the electrochemical performances.

\section{In-situ synthesis}

As-spun all-carbon fibers can be regarded as a scaffold to deposit pseudocapacitive materials such as metal oxide (i.e., $\mathrm{MnO}_{2}$, $\left.\mathrm{Ni}(\mathrm{OH})_{2}, \mathrm{Fe}_{2} \mathrm{O}_{3}, \mathrm{~V}_{2} \mathrm{O}_{5}\right)$, plolypyrrole, and polyaniline in room temperature or using the hydrothermal procedure (Zhang et al., 2018; Li et al., 2019a). The porous CNT or graphene based fibers are hydrophilic, which facilitate the diffusion of deposition ions throughout the fibers. Based on the CNT fiber prepared with CNT aerogel, Xiao et al. (2012) immersed the fiber in ethanol, which was added with $\mathrm{KMnO}_{4}$ aqueous solution. The fiber could reduce aqueous permanganate to obtain $\mathrm{MnO}_{2}$ by the following reaction:

$$
4 \mathrm{MnO}_{4}^{-}+3 \mathrm{C}+\mathrm{H}_{2} \mathrm{O} \rightarrow 4 \mathrm{MnO}_{2}+\mathrm{CO}_{3}^{2-}+2 \mathrm{HCO}_{3}^{-}
$$

The obtained $\mathrm{CNT} / \mathrm{MnO}_{2}$ fibers were designed and applied in a stretchable asymmetric configuration, extending the potential window from 0.8 to $1.5 \mathrm{~V}$ with a high linear specific capacitance of $\sim 157.53 \mu \mathrm{F} / \mathrm{cm}$ at $50 \mathrm{mV} / \mathrm{s}$. The calculated energy density reached from 17.26 to $46.59 \mathrm{nWh} / \mathrm{cm}$ when the power density varying from 7.63 to $61.55 \mu \mathrm{W} / \mathrm{cm}$. By using the similar principle, $\mathrm{Yu}$ et al. (2014b) compared the $\mathrm{MnO}_{2}$ deposited rGO/SWCNT hybrid fiber with different dipping times, which indicated that the $30 \mathrm{~min}$ dipped fiber expressed a highest specific capacitance of $3.3 \mathrm{mF} / \mathrm{cm}$. Zheng et al. (2014) extruded the dispersed GO solution into a rotating coagulation bath with $\mathrm{Mn}^{2+}$ ions and the obtained fiber was further reduced and deposited in $\mathrm{KMnO}_{4}$ solution. $\mathrm{MnO}_{2}$ /graphene fiber was assembled with a MWNT/graphene composite fiber that was spun in a similar method to form an asymmetric supercapacitor. The $\mathrm{MnO}_{2}$ was obviously coated on the surface of fiber and the prepared fiber electrode possessed a high specific capacitance of $59.2 \mathrm{mF} / \mathrm{cm}^{2}$ at a current density of $0.1 \mathrm{~mA} / \mathrm{cm}^{2}$. With the contribution of $\mathrm{MnO}_{2}$, the assembled fiber supercapacitor also obtained a large areal specific capacitance around $33.6 \mathrm{mF} / \mathrm{cm}^{2}$.

Yao's group has dramatically increased the capacitance of the as-spun CNT fiber electrode by inducing the cathode materials based active materials in recent years. The dandelionlike molybdenum-nickel-cobalt ternary oxide (MNCO) nanowire arrays were grown on the surface of the as-prepared solid-spun carbon nanotube fiber as the positive electrode and a vanadium nitride(VN)@C coated CNT fiber as negative electrode to form a fiber-shaped asymmetric supercapacitor (Sun et al., 2017). The growth of the crystal was controlled by the hydrothermal method and largely increased the surface area of the fiber electrode, which obviously enhanced the specific capacitance of the supercapacitor. They then improved the volumetric capacitance of the supercapacitor by alternating the positive electrode to the three-dimensionally aligned zinc-nickel-cobalt oxide $(\mathrm{ZNCO}) @ \mathrm{Ni}(\mathrm{OH})_{2}$ nanowire arrays coated CNT fiber, the capacitance increased from 62.3 to $94.7 \mathrm{~F} / \mathrm{cm}^{3}$ (Zhang Q. et al., 2017). Recently, a $\mathrm{CoNiO}_{2} @ \mathrm{Ni}(\mathrm{OH})_{2}$ grown $\mathrm{CNT}$ fiber electrode was demonstrated by them and assembled with a TiN@VN coated CNT fiber, the supercapacitor shown a higher capacitance of $109.4 \mathrm{~F} / \mathrm{cm}^{3}$ (Li et al., 2019b).

Conducting polymers like polyaniline (PANI) can also be synthesized by such conventional method, Wang et al. (2013) proposed a novel fiber electrode by immersing an as-spun reduced CNT fiber in a aniline monomer contained solution with ethanol and perchloric acid, and then dropped additional ammonium persulfate for further reaction. The as-prepared thread-like supercapacitor could be woven or knitted into textiles alone or together with other devices for energy supplying. The supercapacitor showed the areal specific capacitance of 38 $\mathrm{mF} / \mathrm{cm}^{2}$ compared with $2.3 \mathrm{mF} / \mathrm{cm}^{2}$ of bare CNT fiber. 

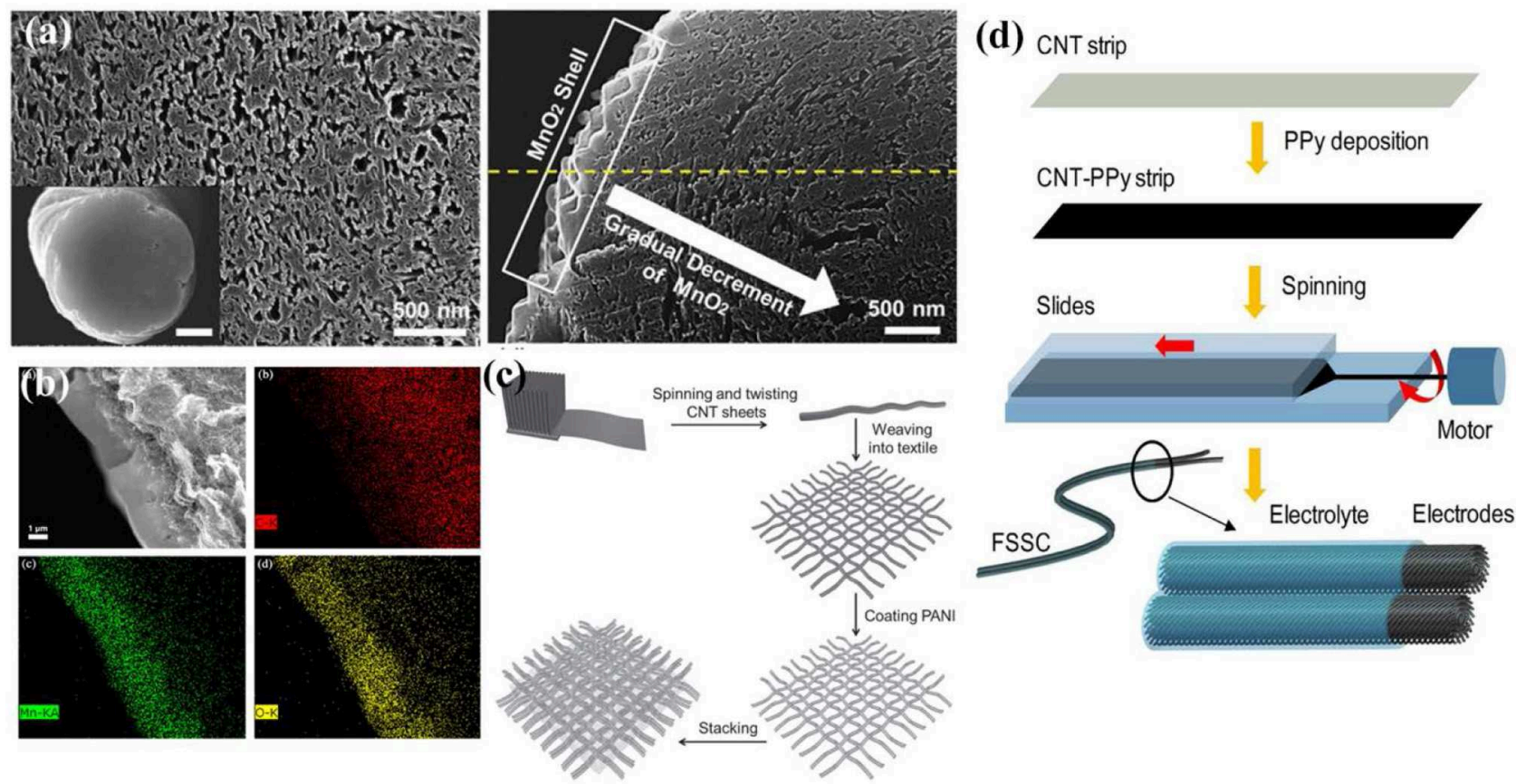

FIGURE 7 | Cross section morphologies of (a) the solid-spun CNT fiber with electrodeposited $\mathrm{MnO}_{2}$ nano-particles (Choi et al., 2014) and (b) EDS of each elements of deposited $\mathrm{MnO}_{2}$ in wet-spun CNT fiber (Lu et al., 2017), (c) schematic fabrication procedures of electrodeposited PANI/CNT textile supercapacitor (Pan et al., 2015), and (d) solid-spun CNT fiber from pre-deposited PPy carbon nanotube film (Xu et al., 2015).

\section{Electrochemical deposition}

Electrochemical deposition refers to a technique in which electrons are transferred through anions and cations in an electrolyte solution under an external electric field and a redox reaction of specific ions occurs on the electrode to form a plating layer (Ju et al., 2012). Electrochemical deposition is widely used and can form nanostructure crystals or conductive polymers to greatly improve the capacitive properties of fiber electrodes. Peng's group firstly applied the electrochemical deposited $\mathrm{MnO}_{2}$ nanoparticles on a MWNT fiber spun from an aligned MWNT forest (Ren et al., 2013b). They used $\mathrm{Mn}\left(\mathrm{CH}_{3} \mathrm{COO}\right)_{2}$ and $\mathrm{Na}_{2} \mathrm{SO}_{4}$ mixed solution as the sources for growing $\mathrm{MnO}_{2}$ particles at a potential range from -0.2 to $0.8 \mathrm{~V}$. The as prepared composite fibers shown a mass specific capacitance of $13.31 \mathrm{~F} / \mathrm{g}$ (or $3.01 \mathrm{mF} / \mathrm{cm}^{2}$ or $0.015 \mathrm{mF} / \mathrm{cm}$ ) when they were in a twisted supercapacitor configuration, and the fibers could further be utilized as a linear Li-battery.

Choi et al. (2014) then utilized the solid-stated spun CNT fiber as a substrate to composite with $\mathrm{MnO}_{2}$ nanoparticles, in which the fiber was immersed in a $\mathrm{MnSO}_{4}$ and $\mathrm{Na}_{2} \mathrm{SO}_{4}$ contained solution. By using a three-electrode system and applying constant voltage of $1.3 \mathrm{~V}$, the flower-like $\mathrm{MnO}_{2}$ nanoflakes were uniformly deposited out and inside the porous CNT fiber (Figure 7a). The consequent specific capacitance of the all-solid-stated fiber-based supercapacitor was $25.4 \mathrm{~F} / \mathrm{cm}^{3}$, and the average energy density was $3.52 \mathrm{mWh} / \mathrm{cm}^{3}$ when the average power densities were $127 \mathrm{~mW} / \mathrm{cm}^{3}$. Based on this principle, we also pioneered a high-performance flexible fiber supercapacitor by using the super-acid spun CNT fiber (shown in Figure 7b; Lu et al., 2017). The as-spun fiber was highly conductive with many micropores, and $\mathrm{MnO}_{2}$ nanoflakes were deposited by electrodeposition. The characterized specific capacitance of the assembled supercapacitor was over $152 \mathrm{~F} / \mathrm{g}\left(\right.$ or $\left.156 \mathrm{~F} / \mathrm{cm}^{3}\right)$, which was about $500 \%$ higher than that of Choi's device at the same scan rate. The measured energy density was $14.1 \mathrm{Wh} / \mathrm{kg}$ at a power density of $202 \mathrm{~W} / \mathrm{kg}$.

Cathode materials like $\mathrm{NiO}$ and $\mathrm{Co}_{3} \mathrm{O}_{4}$ have also been electrochemical deposited by $\mathrm{Su}$ et al. to relatively enhance the capacitance of the bare solid-spun CNT fibers (Su et al., 2015), the CNT@ $\mathrm{Co}_{3} \mathrm{O}_{4}$ yarn-based supercapacitor exhibited a high capacitance of $52.6 \mathrm{mF} / \mathrm{cm}^{2}$ when the CNT@ $\mathrm{NiO}$ also enjoyed a capacitance of $15.2 \mathrm{mF} / \mathrm{cm}^{2}$.

Electrochemical deposited conducting polymers were developed by Peng's group, they incorporated polyaniline with aligned MWNT fibers through an electrochemical analyzer system (Cai et al., 2013). The as-spun fiber was first dipped into the electrolyte containing $\mathrm{H}_{2} \mathrm{SO}_{4}$ and aniline monomer, and the well-infiltrated fiber was then applied with a potential of $0.75 \mathrm{~V}$. To form an all-solid-state fiber supercapacitor, the gel electrolyte was coated the overall fiber as the separator meanwhile. The assembled supercapacitor was fabricated by twisting two composite fibers with a corresponding gravimetric specific capacitance of $274 \mathrm{~F} / \mathrm{g}$ (or $263 \mathrm{mF} / \mathrm{cm}$ ). Furthermore, in their following improvement, two pieces of CNT/PANI composite fiber based textiles was attached together with gel electrolyte to form a thin, lightweight, transparent and flexible supercapacitor (Figure 7c; Pan et al., 2015). The asprepared supercapacitor displayed a high specific capacitance 
of $272.2 \mathrm{~F} / \mathrm{g}$, which could be further integrated in a garment to store the energy that was converted from solar energy. We also Lu et al. (2018) reported a super-elastic wire-like supercapacitor by springing the polyaniline electrodeposited carbon nanotube/graphene hybrid fiber covered with SEBS rubber. The obtained coiled-like supercapacitor presented a superior stretchability of $800 \%$ with a specific capacitance of about $138 \mathrm{~F} / \mathrm{g}$ at a current density of $1 \mathrm{~A} / \mathrm{g}$, which could be further allied in the stretchable textiles to afford the shape deformation of body gesture.

Besides the conducting polyaniline, plolypyrrole (PPy) has also been drawn with a superior pseudocapacitive performance. $\mathrm{Xu}$ et al. (2015) electrodeposited a thin layer of PPy on a aligned CNT film by placing the film between two pieces of stainless steel mesh as the working electrode. The deposited films were then coiled into fibers in wet state by two motors with opposite direction (shown in Figure 7d). High specific capacitance (350 $\mathrm{F} / \mathrm{g}$ ) and extreme stability were then exhibited by the as-prepared fiber electrode in cyclic testing even under bending and twisting.

It can be seen from Table 2 method of electrochemical deposition facilitates the composition between double-layer capacitive carbon nanotube based fibers with high capacitive active materials. In some occasions, such approach can extend to the stretchable fibers which are prepared by wrapping the CNT film on a stretched substrate. The stretchable composite fibers like $\mathrm{CNT} / \mathrm{MnO}_{2}$ (Choi et al., 2015; Yu et al., 2016), CNT/PANI (Chen et al., 2014; Zhang et al., 2015), CNT/PPy (Shang et al., 2015), CNT/PEDOT fibers (Chen et al., 2015), possessed a reasonable electrochemical performances even under a large elongation, showing a potential to be applied in large deformation devices.

\section{SUMMARY}

As the excellent electrode materials, carbon nanotube can be widely used as compatible electrochemical active materials, as well as the carrier or substrate integrated in wearable energy storage devices. In this review paper, we first summarize the main methods that synthesize the carbon nanotube, and briefly describe the development of wet spinning and solidstate spinning methods that are presently utilized to form carbon nanotube fibers, with an extension of approaches to manufacture the composite fibers based on them. We subsequently focus on the potential applications of the fibers in energy storage system, and elaborately discuss how to combine the prepared fibers with nanostructured active materials with different compositing approaches to intrinsically enhance their capacitive performances.

Flexible energy storage technology has been regarded as the key supporting technology for smart wearable electronics. The flexible energy storage device assembled from carbon nanotube fiber-based electrodes has the advantages of being bendable, lightweight, and invisible encapsulation, which will be the foundation of the wearable smart textiles and promotes the rapid development of flexible energy storage devices. The relatively low specific capacitance and yield have been the most drawbacks of carbon nanotube based fibers, it is theoretically to overcome these points from the perspective of fiber structure, proper nano-structured active materials and improvement of existing fiber fabrication method. The summarization of appropriable nanostructured energy materials equally enriches the paths to synthesize high-performance fibers and provides a reference for the development of other novel fiber-based electrode materials in the future.

\section{AUTHOR'S NOTE}

ZL is a lecturer at School of Fashion Engineering, Shanghai University of Engineering Science. He received the B.S. degree in Textile Engineering in 2012 China and the Ph.D degree in Textile Engineering from College of Textiles, Donghua University, China in 2018. He was supported by Chinese Scholarship Council to visit Intelligent Polymer Research Institute, University of Wollongong from 2015 to 2017. He has published more than 5 articles and 1 patent in recent 3 years. His research interests is focus on the fabrication and development of fiberbased wearable devices, nano-structured materials in fibers, and smart textiles.

JF is a Senior Research Fellow at Intelligent Polymer Research Institute, University of Wollongong and a recipient of Australian Research Council DECRA Fellowship. He received the B.S. and MS degree in Engineering (Fibre Science - Textile Chemistry) in 1997 Iran and the Ph.D degree in Material Engineering from School of Mechanical, Materials, Mechatronic and Biomedical Engineering, University of Wollongong, Australia in 2009. He has published more than 150 articles, including one book, five book chapter, 55 journal papers, 1 patent and 68 conference papers in top ranked journals including four papers in the prestigious journal of Science and a growing national and international recognition through various awards and invited presentations. In addition He has supervised 15 Ph.D students. His research focus is now on the development of novel nanomaterials and fibers for use in wearable technologies and biomedical applications.

\section{AUTHOR CONTRIBUTIONS}

All authors listed have made a substantial, direct and intellectual contribution to the work, and approved it for publication.

\section{FUNDING}

This work has been supported by the Australian Research Council under the Discovery Early Career Researcher Award (JF, DE130100517). The authors also are grateful to the support of Shanghai University of Engineering Science (ZL, 2019-96) and Shanghai Municipality of Science and Technology Commission (ZL, 19YF1417700). 


\section{REFERENCES}

Ando, Y., Zhao, X., Sugai, T., and Kumar, M. (2004). Growing carbon nanotubes. Mater. Today 7, 22-29. doi: 10.1016/S1369-7021(04)00446-8

Badaire, S., Pichot, V., Zakri, C., Poulin, P., Launois, P., Vavro, J., et al. (2004). Correlation of properties with preferred orientation in coagulated and stretch-aligned single-wall carbon nanotubes. J. Appl. Phys. 96, 7509-7513. doi: $10.1063 / 1.1810640$

Behabtu, N., Young, C. C., Tsentalovich, D. E., Kleinerman, O., Wang, X., Ma, A. W., et al. (2013). Strong, light, multifunctional fibers of carbon nanotubes with ultrahigh conductivity. Science 339, 182-186. doi: 10.1126/science.1228061

Bucossi, A. R., Cress, C. D., Schauerman, C. M., Rossi, J. E., Puchades, I., Landi, B. J. J., et al. (2015). Enhanced electrical conductivity in extruded single-wall carbon nanotube wires from modified coagulation parameters and mechanical processing. ACS Appl. Mater. Interfaces 7, 27299-27305. doi: 10.1021 /acsami.5b08668

Cai, Z., Li, L., Ren, J., Qiu, L., Lin, H., and Peng, H. (2013). Flexible, weavable and efficient microsupercapacitor wires based on polyaniline composite fibers incorporated with aligned carbon nanotubes. J. Mater. Chem. A 1, 258-261. doi: $10.1039 / \mathrm{C} 2 \mathrm{TA} 00274 \mathrm{D}$

Chen, T., Cai, Z., Qiu, L., Li, H., Ren, J., Lin, H., et al. (2013). Synthesis of aligned carbon nanotube composite fibers with high performances by electrochemical deposition. J. Mater. Chem. A 1, 2211-2216. doi: 10.1039/C2TA01039A

Chen, T., Hao, R., Peng, H., and Dai, L. (2015). High-performance, stretchable, wire-shaped supercapacitors. Angew. Chem. Int. Ed. 54, 618-622. doi: 10.1002/ange.201409385

Chen, X., Lin, H., Deng, J., Zhang, Y., Sun, X., Chen, P., et al. (2014). Electrochromic fiber-shaped supercapacitors. Adv. Mater. 26, 8126-8132. doi: 10.1002/adma.201403243

Chhowalla, M., and Unalan, H. E. (2011). "Cathodic arc discharge for synthesis of carbon nanoparticles," in Plasma Processing of Nanomaterials (New York, NY: Taylor \& Francis), 147.

Choi, C., Kim, K. M., Kim, K. J., Lepró, X., Spinks, G. M., Baughman, R. H., et al. (2016). Improvement of system capacitance via weavable superelastic biscrolled yarn supercapacitors. Nat. Commun. 7:13811. doi: 10.1038/ncomms13811

Choi, C., Kim, S. H., Sim, H. J., Lee, J. A., Choi, A. Y., Kim, Y. T., et al. (2015). Stretchable, weavable coiled carbon nanotube/MnO2/polymer fiber solid-state supercapacitors. Sci. Rep. 5:9387. doi: 10.1038/srep09387

Choi, C., Lee, J. A., Choi, A. Y., Kim, Y. T., Lepró, X., Lima, M. D., et al. (2014). Flexible supercapacitor made of carbon nanotube yarn with internal pores. Adv. Mater. 26, 2059-2065. doi: 10.1002/adma.201304736

Ci, L., Punbusayakul, N., Wei, J., Vajtai, R., Talapatra, S., and Ajayan, P. M. (2007). Multifunctional macroarchitectures of double-walled carbon nanotube fibers. Adv. Mater. 19, 1719-1723. doi: 10.1002/adma.200602520

Dalton, A. B., Collins, S., Munoz, E., Razal, J. M., Ebron, V. H., Ferraris, J. P., et al. (2003). Super-tough carbon-nanotube fibres. Nature 423:703. doi: $10.1038 / 423703 a$

Danilov, P. A., Ionin, A. A., Kudryashov, S. I., Makarov, S. V., Mel'nik, N. N., Rudenko, A. A., et al. (2014). Femtosecond laser ablation of single-wall carbon nanotube-based material. Laser Phys. Lett. 11:106101. doi: 10.1088/1612-2011/11/10/106101

Das, R., Shahnavaz, Z., Ali, M. E., Islam, M. M., and Hamid, S. B. A. (2016). Can we optimize arc discharge and laser ablation for well-controlled carbon nanotube synthesis? Nanoscale Res. Lett. 11:510. doi: 10.1186/s11671-0161730-0

Davis, V. A., Parra-Vasquez, A. N., Green, M. J., Rai, P. K., Behabtu, N., Prieto, V., et al. (2009). True solutions of single-walled carbon nanotubes for assembly into macroscopic materials. Nat. Nanotechnol. 4, 830-834. doi: 10.1038/nnano.2009.302

Ebbesen, T., and Ajayan, P. (1992). Large-scale synthesis of carbon nanotubes. Nature 358, 220-222. doi: 10.1038/358220a0

Ericson, L. M., Fan, H., Peng, H., Davis, V. A., Zhou, W., Sulpizio, J., et al. (2004). Macroscopic, neat, single-walled carbon nanotube fibers. Science 305, 1447-1450. doi: 10.1126/science.1101398

Feng, J.-M., Wang, R., Li, Y.-L., Zhong, X.-H., Cui, L., Guo, Q.-J., et al. (2010). One-step fabrication of high quality double-walled carbon nanotube thin films by a chemical vapor deposition process. Carbon N. Y. 48, 3817-3824. doi: 10.1016/j.carbon.2010.06.046
Foroughi, J., Spinks, G. M., Antiohos, D., Mirabedini, A., Gambhir, S., Wallace, G. G., et al. (2014). Highly conductive carbon nanotube-graphene hybrid yarn. Adv. Funct. Mater. 24, 5859-5865. doi: 10.1002/adfm.201401412

Foroughi, J., Spinks, G. M., Aziz, S., Mirabedini, A., Jeiranikhameneh, A., Wallace, G. G., et al. (2016). Knitted carbon-nanotube-sheath/spandex-core elastomeric yarns for artificial muscles and strain sensing. ACS Nano 10, 9129-9135. doi: 10.1021/acsnano.6b04125

Foroughi, J., Spinks, G. M., Wallace, G. G., Oh, J., Kozlov, M. E., Fang, S., et al. (2011). Torsional carbon nanotube artificial muscles. Science 334, 494-497. doi: $10.1126 /$ science. 1211220

Guo, T., Diener, M., Chai, Y., Alford, M., Haufler, R., McClure, S., et al. (1992). Uranium stabilization of C28: a tetravalent fullerene. Science 257, 1661-1664. doi: $10.1126 /$ science.257.5077.1661

Guo, T., Nikolaev, P., Thess, A., Colbert, D., and Smalley, R. (1995). Catalytic growth of single-walled manotubes by laser vaporization. Chem. Phys. Lett. 243, 49-54. doi: 10.1016/0009-2614(95)00825-O

Guo, W., Liu, C., Sun, X., Yang, Z., Kia, H. G., and Peng, H. (2012). Aligned carbon nanotube/polymer composite fibers with improved mechanical strength and electrical conductivity. J. Mater. Chem. 22, 903-908. doi: 10.1039/C1JM13769G

Haines, C. S., Lima, M. D., Li, N., Spinks, G. M., Foroughi, J., Madden, J. D., et al. (2014). Artificial muscles from fishing line and sewing thread. Science 343, 868-872. doi: 10.1126/science.1246906

Huang, Y., Huang, Y., Zhu, M., Meng, W., Pei, Z., Liu, C., et al. (2015). Magneticassisted, self-healable, yarn-based supercapacitor. ACS Nano 9, 6242-6251. doi: 10.1021/acsnano.5b01602

Huang, Y., Zhu, M., Huang, Y., Li, H., Pei, Z., Xue, Q., et al. (2016). A modularization approach for linear-shaped functional supercapacitors. $J$. Mater. Chem. A 4, 4580-4586. doi: 10.1039/C6TA00753H

Iijima, S. (1991). Helical microtubules of graphitic carbon. Nature 354, 56-58 doi: $10.1038 / 354056 \mathrm{a} 0$

Ikegami, T., Nakanishi, F., Uchiyama, M., and Ebihara, K. (2004). Optical measurement in carbon nanotubes formation by pulsed laser ablation. Thin Solid Films 457, 7-11. doi: 10.1016/j.tsf.2003.12.033

Jalili, R., Razal, J. M., Innis, P. C., and Wallace, G. G. (2011). One-step wetspinning process of poly (3, 4-ethylenedioxythiophene): poly (styrenesulfonate) fibers and the origin of higher electrical conductivity. Adv. Funct. Mater. 21, 3363-3370. doi: 10.1002/adfm.201100785

Jalili, R., Razal, J. M., and Wallace, G. G. (2012). Exploiting high quality PEDOT: PSS-SWNT composite formulations for wet-spinning multifunctional fibers. $J$. Mater. Chem. 22, 25174-25182. doi: 10.1039/c2jm35148j

Jalili, R., Razal, J. M., and Wallace, G. G. (2013). Wet-spinning of PEDOT: PSS/functionalized-SWNTs composite: a facile route toward production of strong and highly conducting multifunctional fibers. Sci. Rep. 3:3438. doi: 10.1038/srep03438

Jang, E. Y., Kang, T. J., Im, H., Baek, S. J., Kim, S., Jeong, D. H., et al. (2009). Macroscopic single-walled-carbon-nanotube fiber self-assembled by dip-coating method. Adv. Mater. 21, 4357-4361. doi: 10.1002/adma.200900480

Jarosz, P., Schauerman, C., Alvarenga, J., Moses, B., Mastrangelo, T., Raffaelle, R., et al. (2011). Carbon nanotube wires and cables: near-term applications and future perspectives. Nanoscale 3, 4542-4553. doi: 10.1039/c1nr10814j

Jarosz, P. R., Shaukat, A., Schauerman, C. M., Cress, C. D., Kladitis, P. E., Ridgley, R. D., et al. (2012). High-performance, lightweight coaxial cable from carbon nanotube conductors. ACS Appl. Mater. Interfaces 4, 1103-1109. doi: $10.1021 / \mathrm{am} 201729 \mathrm{~g}$

Jha, N., Ramesh, P., Bekyarova, E., Itkis, M. E., and Haddon, R. C. (2012). High energy density supercapacitor based on a hybrid carbon nanotubereduced graphite oxide architecture. Adv. Energy Mater. 2, 438-444. doi: 10.1002/aenm.201100697

Jiang, K., Li, Q., and Fan, S. (2002). Nanotechnology: spinning continuous carbon nanotube yarns. Nature 419, 801-801. doi: 10.1038/419801a

Journet, C., and Bernier, P. (1998). Production of carbon nanotubes. Appl. Phys A 67, 1-9. doi: 10.1007/s003390050731

Ju, H., Lee, J. K., Lee, J., and Lee, J. (2012). Fast and selective Cu2O nanorod growth into anodic alumina templates via electrodeposition. Curr. Appl. Phys .12, 60-64. doi: 10.1016/j.cap.2011.04.042

Jung, S.-H., Kim, M.-R., Jeong, S.-H., Kim, S.-U., Lee, O.-J., Lee, K.-H., et al. (2003). High-yield synthesis of multi-walled carbon nanotubes by arc discharge in liquid nitrogen. Appl. Phys. A 76, 285-286. doi: 10.1007/s00339-002-1718-8 
Kozlov, M. E., Capps, R. C., Sampson, W. M., Ebron, V. H., Ferraris, J. P., and Baughman, R. H. (2005). Spinning solid and hollow polymer-free carbon nanotube fibers. Adv. Mater. 17, 614-617. doi: 10.1002/adma.200401130

Kumar, M., and Ando, Y. (2010). Chemical vapor deposition of carbon nanotubes: a review on growth mechanism and mass production. J. Nanosci. Nanotechnol. 10, 3739-3758. doi: 10.1166/jnn.2010.2939

Li, G.-X., Hou, P.-X., Luan, J., Li, J.-C., Li, X., Wang, H., et al. (2018). A $\mathrm{MnO}_{2}$ nanosheet/single-wall carbon nanotube hybrid fiber for wearable solid-state supercapacitors. Carbon N. Y. 140, 634-643. doi: 10.1016/j.carbon.2018.09.011

Li, H., He, J., Cao, X., Kang, L., He, X., Xu, H., et al. (2017). All solid-state V2O5-based flexible hybrid fiber supercapacitors. J. Power Sources 371, 18-25. doi: 10.1016/j.jpowsour.2017.10.031

Li, Q., Zhang, Q., Liu, C., Sun, J., Guo, J., Zhang, J., et al. (2019a). Flexible all-solidstate fiber-shaped $\mathrm{Ni}-\mathrm{Fe}$ batteries with high electrochemical performance. J. Mater. Chem. A 7, 520-530. doi: 10.1039/C8TA09822K

Li, Q., Zhang, Q., Sun, J., Liu, C., Guo, J., He, B., et al. (2019b). All hierarchical core-shell heterostructures as novel binder-free electrode materials for ultrahigh-energy-density wearable asymmetric supercapacitors. Adv. Sci. 6:1801379. doi: 10.1002/advs.201801379

Li, S., Zhang, X., Zhao, J., Meng, F., Xu, G., Yong, Z., et al. (2012). Enhancement of carbon nanotube fibres using different solvents and polymers. Compos. Sci. Technol. 72, 1402-1407. doi: 10.1016/j.compscitech.2012.05.013

Li, Y.-L., Kinloch, I. A., and Windle, A. H. (2004). Direct spinning of carbon nanotube fibers from chemical vapor deposition synthesis. Science 304, 276-278. doi: 10.1126/science.1094982

Lu, Z., Chao, Y., Ge, Y., Foroughi, J., Zhao, Y., Wang, C., et al. (2017). Highperformance hybrid carbon nanotube fibers for wearable energy storage. Nanoscale 9, 5063-5071. doi: 10.1039/C7NR00408G

Lu, Z., Foroughi, J., Wang, C., Long, H., and Wallace, G. G. (2018). Superelastic hybrid CNT/graphene fibers for wearable energy storage. Adv. Energy Mater. 8:1702047. doi: 10.1002/aenm.201702047

Ma, A. W., Nam, J., Behabtu, N., Mirri, F., Young, C. C., Dan, B., et al. (2013). Scalable formation of carbon nanotube films containing highly aligned whiskerlike crystallites. Ind. Eng. Chem. Res. 52, 8705-8713. doi: $10.1021 /$ ie $303042 \mathrm{x}$

Ma, W., Chen, S., Yang, S., Chen, W., Weng, W., and Zhu, M. (2016). Bottomup fabrication of activated carbon fiber for all-solid-state supercapacitor with excellent electrochemical performance. ACS Appl. Mater. Interfaces 8, 14622-14627. doi: 10.1021/acsami.6b04026

Ma, W., Liu, L., Yang, R., Zhang, T., Zhang, Z., Song, L., et al. (2009). Monitoring a micromechanical process in macroscale carbon nanotube films and fibers. $A d v$. Mater. 21, 603-608. doi: 10.1002/adma.200801335

Ma, Y., Li, P., Sedloff, J. W., Zhang, X., Zhang, H., and Liu, J. (2015). Conductive graphene fibers for wire-shaped supercapacitors strengthened by unfunctionalized few-walled carbon nanotubes. ACS Nano 9, 1352-1359. doi: $10.1021 / \mathrm{nn} 505412 \mathrm{v}$

Miaudet, P., Badaire, S., Maugey, M., Derre, A., Pichot, V., Launois, P., et al. (2005). Hot-drawing of single and multiwall carbon nanotube fibers for high toughness and alignment. Nano Lett. 5, 2212-2215. doi: 10.1021/nl051419w

Munoz, E., Dalton, A. B., Collins, S., Kozlov, M., Razal, J., Coleman, J. N., et al. (2004). Multifunctional carbon nanotube composite fibers. Adv. Eng. Mater. 6, 801-804. doi: 10.1002/adem.200400092

Pan, S., Lin, H., Deng, J., Chen, P., Chen, X., Yang, Z., et al. (2015). Novel wearable energy devices based on aligned carbon nanotube fiber textiles. Adv. Energy Mater. 5:1401438. doi: 10.1002/aenm.201401438

Parkansky, N., Boxman, R., Alterkop, B., Zontag, I., Lereah, Y., and Barkay, Z. (2004). Single-pulse arc production of carbon nanotubes in ambient air. J. Phys. D Appl. Phys. 37:2715. doi: 10.1088/0022-3727/37/19/015

Parra-Vasquez, A. N. G., Behabtu, N., Green, M. J., Pint, C. L., Young, C. C., Schmidt, J., et al. (2010). Spontaneous dissolution of ultralong single-and multiwalled carbon nanotubes. ACS Nano 4, 3969-3978. doi: $10.1021 / \mathrm{nn} 100864 \mathrm{v}$

Peng, H., Sun, X., Cai, F., Chen, X., Zhu, Y., Liao, G., et al. (2009). Electrochromatic carbon nanotube/polydiacetylene nanocomposite fibres. Nat. Nanotechnol. 4, 738-741. doi: 10.1038/nnano.2009.264

Pillai, S. K., Augustyn, W. G., Rossouw, M. H., and McCrindle, R. I. (2008). The effect of calcination on multi-walled carbon nanotubes produced by Dc-Arc discharge. J. Nanosci. Nanotechnol. 8, 3539-3544. doi: 10.1166/jnn.2008.115
Prasek, J., Drbohlavova, J., Chomoucka, J., Hubalek, J., Jasek, O., Adam, V., et al. (2011). Methods for carbon nanotubes synthesis-review. J. Mater. Chem. 21:15872. doi: 10.1039/c1jm12254a

Ramesh, S., Ericson, L. M., Davis, V. A., Saini, R. K., Kittrell, C., Pasquali, M., et al. (2004). Dissolution of pristine single walled carbon nanotubes in superacids by direct protonation. J. Phys. Chem. B 108, 8794-8798. doi: 10.1021/jp036971t

Randeniya, L. K., Bendavid, A., Martin, P. J., and Tran, C. D. (2010). Composite yarns of multiwalled carbon nanotubes with metallic electrical conductivity. Small 6, 1806-1811. doi: 10.1002/smll.201000493

Ren, J., Bai, W., Guan, G., Zhang, Y., and Peng, H. (2013a). Flexible and weaveable capacitor wire based on a carbon nanocomposite fiber. Adv. Mater. 25, 5965-5970. doi: 10.1002/adma.201302498

Ren, J., Li, L., Chen, C., Chen, X., Cai, Z., Qiu, L., et al. (2013b). Twisting carbon nanotube fibers for both wire-shaped micro-supercapacitor and micro-battery. Adv. Mater. 25, 1155-1159. doi: 10.1002/adma.201203445

Shang, Y., Wang, C., He, X., Li, J., Peng, Q., Shi, E., et al. (2015). Self-stretchable, helical carbon nanotube yarn supercapacitors with stable performance under extreme deformation conditions. Nano Energy 12, 401-409. doi: 10.1016/j.nanoen.2014.11.048

Shimotani, K., Anazawa, K., Watanabe, H., and Shimizu, M. (2001). New synthesis of multi-walled carbon nanotubes using an arc discharge technique under organic molecular atmospheres. Appl. Phys. A 73, 451-454. doi: $10.1007 / \mathrm{s} 003390100821$

Steiner, S. A. III, Baumann, T. F., Bayer, B. C., Blume, R., Worsley, M. A., Moberlychan, W. J., et al. (2009). Nanoscale zirconia as a nonmetallic catalyst for graphitization of carbon and growth of single-and multiwall carbon nanotubes. J. Am. Chem. Soc. 131, 12144-12154. doi: 10.1021/ja902913r

Steinmetz, J., Glerup, M., Paillet, M., Bernier, P., and Holzinger, M. (2005). Production of pure nanotube fibers using a modified wet-spinning method. Carbon N. Y. 43, 2397-2400. doi: 10.1016/j.carbon.2005.03.047

$\mathrm{Su}, \mathrm{F}$., Lv, X., and Miao, M. (2015). High-performance two-ply yarn supercapacitors based on carbon nanotube yarns dotted with $\mathrm{Co} 3 \mathrm{O} 4$ and $\mathrm{NiO}$ nanoparticles. Small 11, 854-861. doi: 10.1002/smll.201401862

$\mathrm{Su}, \mathrm{F}$., and Miao, M. (2014a). Asymmetric carbon nanotube-MnO2 two-ply yarn supercapacitors for wearable electronics. Nanotechnology 25:135401. doi: 10.1088/0957-4484/25/13/135401

$\mathrm{Su}$, F., and Miao, M. (2014b). Flexible, high performance two-ply yarn supercapacitors based on irradiated carbon nanotube yarn and PEDOT/PSS. Electrochim. Acta 127, 433-438. doi: 10.1016/j.electacta.2014.02.064

$\mathrm{Su}, \mathrm{F}$., Miao, M., Niu, H., and Wei, Z. (2014). Gamma-irradiated carbon nanotube yarn as substrate for high-performance fiber supercapacitors. ACS Appl. Mater. Interfaces 6, 2553-2560. doi: 10.1021/am404967x

Sun, G., Liu, J., Zhang, X., Wang, X., Li, H., Yu, Y., et al. (2014a). Fabrication of ultralong hybrid microfibers from nanosheets of reduced graphene oxide and transition-metal dichalcogenides and their application as supercapacitors. Angew. Chem. Int. Ed. 126, 12784-12788. doi: 10.1002/ange.201405325

Sun, G., Zhang, X., Lin, R., Yang, J., Zhang, H., and Chen, P. (2015). Hybrid fibers made of molybdenum disulfide, reduced graphene oxide, and multi-walled carbon nanotubes for solid-state, flexible, asymmetric supercapacitors. Angew. Chem. Int. Ed. 54, 4651-4656. doi: 10.1002/anie.201411533

Sun, H., You, X., Deng, J., Chen, X., Yang, Z., Ren, J., et al. (2014b). Novel graphene/carbon nanotube composite fibers for efficient wire-shaped miniature energy devices. Adv. Mater. 26, 2868-2873. doi: 10.1002/adma.2013 05188

Sun, J., Zhang, Q., Wang, X., Zhao, J., Guo, J., Zhou, Z., et al. (2017). Constructing hierarchical dandelion-like molybdenum-nickel-cobalt ternary oxide nanowire arrays on carbon nanotube fiber for high-performance wearable fiber-shaped asymmetric supercapacitors. J. Mater. Chem. A 5, 21153-21160. doi: 10.1039/C7TA06353A

Thess, A., Lee, R., Nikolaev, P., Dai, H., Petit, P., Robert, J., et al. (1996). Crystalline ropes of metallic carbon nanotubes. Science 273, 483-487. doi: $10.1126 /$ science.273.5274.483

Vigolo, B., Pénicaud, A., Coulon, C., Sauder, C., Pailler, R., Journet, C., et al. (2000). Macroscopic fibers and ribbons of oriented carbon nanotubes. Science 290, 1331-1334. doi: 10.1126/science.290.5495.1331

Vigolo, B., Poulin, P., Lucas, M., Launois, P., and Bernier, P. (2002). Improved structure and properties of single-wall carbon nanotube spun fibers. Appl. Phys. Lett. 81, 1210-1212. doi: 10.1063/1.1497706 
Wang, K., Meng, Q., Zhang, Y., Wei, Z., and Miao, M. (2013). High-performance two-ply yarn supercapacitors based on carbon nanotubes and polyaniline nanowire arrays. Adv. Mater. 25, 1494-1498. doi: 10.1002/adma.201204598

Xiao, X., Li, T., Yang, P., Gao, Y., Jin, H., Ni, W., et al. (2012). Fiber-based all-solidstate flexible supercapacitors for self-powered systems. ACS Nano 6, 9200-9206. doi: $10.1021 / \mathrm{nn} 303530 \mathrm{k}$

Xu, G., Zhao, J., Li, S., Zhang, X., Yong, Z., and Li, Q. (2011). Continuous electrodeposition for lightweight, highly conducting and strong carbon nanotube-copper composite fibers. Nanoscale 3, 4215-4219. doi: $10.1039 / \mathrm{cln} 10571 \mathrm{j}$

Xu, R., Wei, J., Guo, F., Cui, X., Zhang, T., Zhu, H., et al. (2015). Highly conductive, twistable and bendable polypyrrole-carbon nanotube fiber for efficient supercapacitor electrodes. RSC Adv. 5, 22015-22021. doi: 10.1039/C5RA01917F

Yao, F., Pham, D. T., and Lee, Y. H. (2015). Carbon-based materials for lithium-ion batteries, electrochemical capacitors, and their hybrid devices. ChemSusChem 8, 2284-2311. doi: 10.1002/cssc.201403490

Yao, Y., Li, Q., Zhang, J., Liu, R., Jiao, L., Zhu, Y. T., et al. (2007). Temperaturemediated growth of single-walled carbon-nanotube intramolecular junctions. Nat. Mater. 6:283. doi: 10.1038/nmat1865

Yu, D., and Dai, L. (2009). Self-assembled graphene/carbon nanotube hybrid films for supercapacitors. J. Phys. Chem. Lett. 1, 467-470. doi: 10.1021/jz90 03137

Yu, D., Goh, K., Wang, H., Wei, L., Jiang, W., Zhang, Q., et al. (2014a). Scalable synthesis of hierarchically structured carbon nanotube-graphene fibres for capacitive energy storage. Nat. Nanotechnol. 9, 555-562. doi: 10.1038/nnano.2014.93

Yu, D., Goh, K., Zhang, Q., Wei, L., Wang, H., Jiang, W., et al. (2014b). Controlled functionalization of carbonaceous fibers for asymmetric solid-state micro-supercapacitors with high volumetric energy density. Adv. Mater. 26, 6790-6797. doi: 10.1002/adma.201403061

Yu, J., Lu, W., Smith, J. P., Booksh, K. S., Meng, L., Huang, Y., et al. (2016). A high performance stretchable asymmetric fiber-shaped supercapacitor with a core-sheath helical structure. Adv. Energy Mater. 7:1600976. doi: 10.1002/aenm.201600976

Zhang, D., Zhang, Y., and Miao, M. (2014). Metallic conductivity transition of carbon nanotube yarns coated with silver particles. Nanotechnology 25:275702. doi: 10.1088/0957-4484/25/27/275702

Zhang, K., Li, T., Ling, L., Lu, H., Tang, L., Li, C., et al. (2017). Facile synthesis of high density carbon nanotube array by a deposition-growthdensification process. Carbon N. Y. 114, 435-440. doi: 10.1016/j.carbon.2016. 12.047

Zhang, L. L., Zhou, R., and Zhao, X. (2010). Graphene-based materials as supercapacitor electrodes. J. Mater. Chem. 20, 5983-5992. doi: $10.1039 / \mathrm{c} 000417 \mathrm{k}$
Zhang, M., Atkinson, K. R., and Baughman, R. H. (2004). Multifunctional carbon nanotube yarns by downsizing an ancient technology. Science 306, 1358-1361. doi: 10.1126/science.1104276

Zhang, Q., Xu, W., Sun, J., Pan, Z., Zhao, J., Wang, X., et al. (2017). Constructing ultrahigh-capacity zinc-nickel-cobalt oxide@ Ni (OH) 2 core-shell nanowire arrays for high-performance coaxial fiber-shaped asymmetric supercapacitors. Nano Lett. 17, 7552-7560. doi: 10.1021/acs.nanolett.7b03507

Zhang, Q., Zhou, Z., Pan, Z., Sun, J., He, B., Li, Q., et al. (2018). All-metalorganic framework-derived battery materials on carbon nanotube fibers for wearable energy-storage device. Adv. Sci. 5:1801462. doi: 10.1002/advs.2018 01462

Zhang, S., Ji, C., Bian, Z., Yu, P., Zhang, L., Liu, D., et al. (2012). Porous, platinum nanoparticle-adsorbed carbon nanotube yarns for efficient fiber solar cells. ACS Nano 6, 7191-7198. doi: 10.1021/nn3022553

Zhang, S., Zhu, L., Minus, M. L., Chae, H. G., Jagannathan, S., Wong, C.-P., et al. (2008). Solid-state spun fibers and yarns from 1-mm long carbon nanotube forests synthesized by water-assisted chemical vapor deposition. J. Mater. Sci. 43, 4356-4362. doi: 10.1007/s10853-008-2558-5

Zhang, X., Jiang, K., Feng, C., Liu, P., Zhang, L., Kong, J., et al. (2006). Spinning and processing continuous yarns from 4 -inch wafer scale super-aligned carbon nanotube arrays. Adv. Mater. 18, 1505-1510. doi: 10.1002/adma.200502528

Zhang, X., Li, Q., Tu, Y., Li, Y., Coulter, J. Y., Zheng, L., et al. (2007). Strong carbonnanotube fibers spun from long carbon-nanotube arrays. Small 3, 244-248. doi: $10.1002 / \mathrm{smll} .200600368$

Zhang, Z., Deng, J., Li, X., Yang, Z., He, S., Chen, X., et al. (2015). Superelastic supercapacitors with high performances during stretching. Adv. Mater. 27, 356-362. doi: 10.1002/adma.201404573

Zheng, B., Huang, T., Kou, L., Zhao, X., Gopalsamy, K., and Gao, C. (2014). Graphene fiber-based asymmetric micro-supercapacitors. J. Mater. Chem. A 2, 9736-9743. doi: 10.1039/C4TA01868K

Zheng, L., Zhang, X., Li, Q., Chikkannanavar, S. B., Li, Y., Zhao, Y., et al. (2007). Carbon-nanotube cotton for large-scale fibers. Adv. Mater. 19, 2567-2570. doi: 10.1002/adma.200602648

Conflict of Interest Statement: The authors declare that the research was conducted in the absence of any commercial or financial relationships that could be construed as a potential conflict of interest.

Copyright (C) 2019 Lu, Raad, Safaei, Xi, Liu and Foroughi. This is an open-access article distributed under the terms of the Creative Commons Attribution License (CC $B Y)$. The use, distribution or reproduction in other forums is permitted, provided the original author(s) and the copyright owner(s) are credited and that the original publication in this journal is cited, in accordance with accepted academic practice. No use, distribution or reproduction is permitted which does not comply with these terms. 